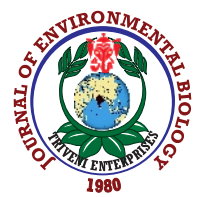

\title{
Effect of thyroxine hormone towards growth and survival of climbing perch (Anabas testudineus, Bloch) larvae
}

\author{
A.N. Alang ${ }^{1}$, Z. Hassan ${ }^{1}$, A. Christianus ${ }^{1,2}$ and Z. Zulperi ${ }^{1,2 *}$ \\ ${ }^{1}$ Department of Aquaculture, Faculty of Agriculture, Universiti Putra Malaysia, 43400 UPM Serdang, Selangor, Malaysia \\ ${ }^{2}$ Laboratory of Marine Biotechnology, Institute of Bioscience, Universiti Putra Malaysia, 43400 UPM Serdang, Selangor, Malaysia \\ *Corresponding Author Email : zarirah@upm.edu.my
}

\begin{tabular}{lll}
\hline Paper received: 23.01 .2020 & Revised received: 16.03 .2020 & Accepted: 14.08 .2020 \\
\hline
\end{tabular}

\section{Abstract}

Aim: Climbing perch (Anabas testudineus) is a popular fish in Asian countries. However, the long culture period and slow growth of the species has made it unpopular among fish farmers. Thyroxine $\left(\mathrm{T}_{4}\right)$ is a hormone that functions as a growth precursor in all mammals including teleosts. This research aimed to study the effect of $\mathrm{T}_{4}$ on growth and survival of climbing perch.

Methodology: Larvae of climbing perch were used to perform the experiment at different frequencies of $\mathrm{T}_{4}$ treatments (Group 1: 1X0.5 ppm $\mathrm{T}_{4}$; Group 2:

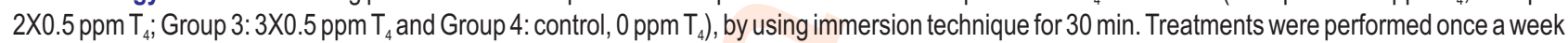
for three continuous weeks.

Results: The highest survival of larvae was recorded from Group 2 $(66.7 \%)$ as compared to control group (52.5\%). The length and weight of fish treated with T4 showed significant increment $(p<0.05)$, while the best results were recorded at week 7 from Group 2 (length: 41.75 $\mathrm{cm}$, weight: $1.47 \mathrm{~g}$ ) compared to control group (length: $33.46 \pm 0.93$ $\mathrm{cm}$, weight: $0.71 \mathrm{~g}$ ), respectively.

Interpretation: The use of $\mathrm{T}_{4}$ at a specific dosage $(0.5 \mathrm{ppm})$ at twotime treatment was sufficient to increase the growth rate of climbing perch larvae, thereby reducing the cost of hatchery time to reach the market size.

Key words: Anabas testudineus, Climbing perch, Hormone, Thyroxine

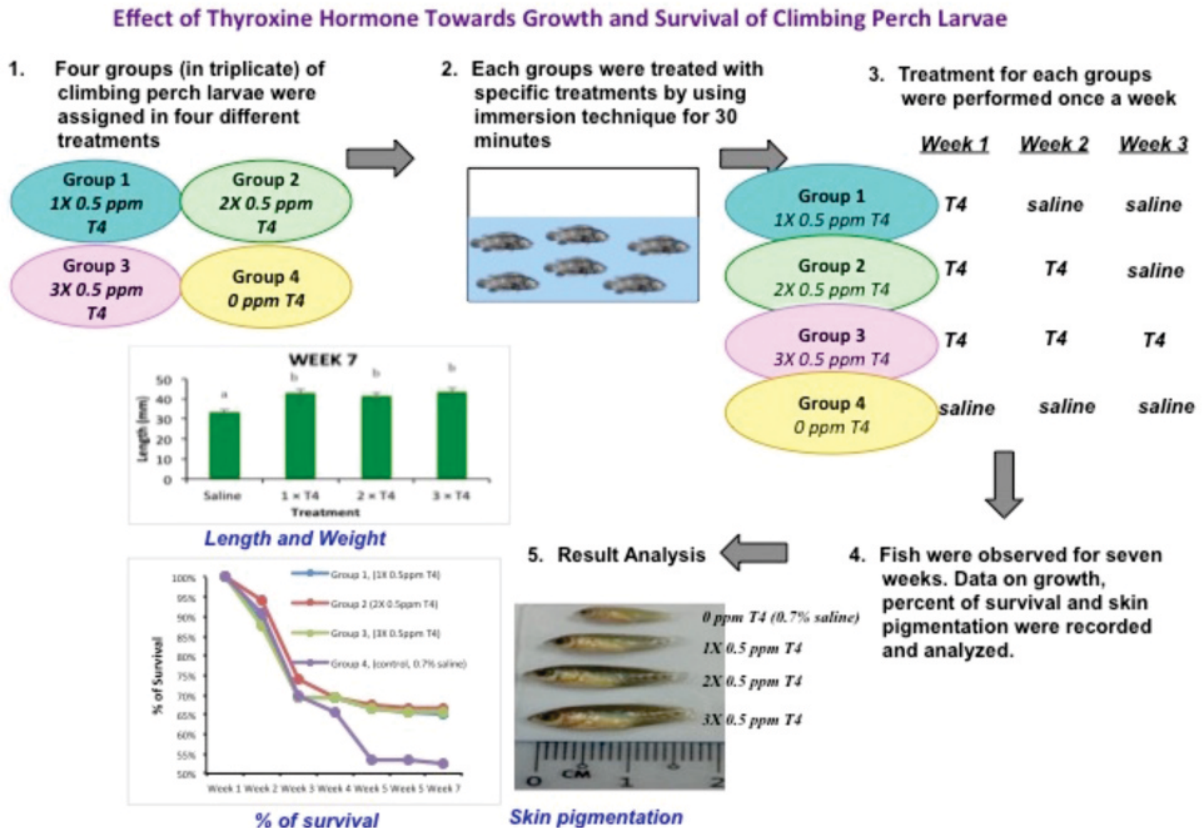

How to cite : Alang, A.N., Z. Hassan, A. Christianus and Z. Zulperi: Effect of thyroxine hormone towards growth and survival of climbing perch (Anabas testudineus, Bloch) larvae. J. Environ. Biol., 41, 1230-1238 (2020). 


\section{Introduction}

Fish has become an important source of food for humans as it contains high amount of protein that can support growth and development. In human diets, fish contributes approximately $16 \%$ of animal protein (FAO, 2017; Young et al., 2016). The total fish supply is expected to increase from 154 million tons in 2011 to 186 million tons in 2030, with aquaculture entirely responsible for the increase (Kobayashi et al., 2015). The aquaculture industry in Malaysia is rapidly developing as many companies are becoming more involved in fish farming with a total value production more than RM3.9 million in 2017 (Department of Fisheries Malaysia, 2017). Anabas testudineus (Bloch, 1972) also known as climbing perch is a native specie of Malaysia and is also found in many Asian countries including Indonesia, Thailand, Bangladesh, Pakistan and India (Jamsari et al., 2010; Morioka et al., 2009). They are tropical climate species that live between $22^{\circ} \mathrm{C}$ to $30^{\circ} \mathrm{C}$ in freshwater and brackish environment. This species can be found in canals, lakes, ponds, estuaries as well as rice paddy fields (Rosman and Zulperi, 2019; Vidthayanon, 2002). The fish has an ability to breathe in air, thus it can be reared easily (Morioka et al., 2009; Hughes et al., 1973). However, limited studies on this species have hindered its development as an aquaculture species, thus affecting its production to fulfill the market demand. One problem that farmers face is the late development of fish larvae after hatching, coupled with slow larval growth that can reduce the farmer's production. The long culture period and slow growth of climbing perch has made it unpopular among fish farmers.

Thyroxine is a hormone that functions as a growth precursor in living organisms including mammals, amphibians and teleosts (Norris and Carr, 2013; Dickhoff et al., 1990). The application of thyroxine hormone in fish gives a positive impact towards its development, as the hormone itself functions as an important factor in the maintenance and functions of digestion, heart, muscle and bones (Dolomatov and Medical, 2013; Chang et al., 2012). Thyroxine is secreted in the bloodstream by thyroid gland (Norris and Carr, 2013). Thyroxine $\left(\mathrm{T}_{4}\right)$ and triiodothyroxine $\left(T_{3}\right)$ is regulated by a feedback loop system, which is under the control of hypothalamus situated in brain. Hypothalamus secretes thyrotropin-releasing hormone and stimulates pituitary glands to produce thyroid-stimulating hormone. This hormone eventually stimulates the production of thyroid hormones, $\mathrm{T}_{4}$ and $\mathrm{T}_{3}$ by thyroid gland. Many researchers have conducted studies on the effect of $T_{4}$ hormone on the early development of fish, by adding this hormone as supplement in the fish diet or by using an immersion technique of $\mathrm{T}_{4}$ (Jones et al., 2017; Manzon and Manzon, 2017). Based on previous studies of milk fish larvae development, immersion of accurate amount of $\mathrm{T}_{4}$ hormone fastens the egg-yolk absorption and minimizes the time needed for hatchery rearing (Power et al., 2001; Lam et al., 1985). Also, treatment of $0.1 \mathrm{mg} \mathrm{l}^{-1} \mathrm{~T}_{4}$ hormone through immersion technique in pink zebrafish larvae showed that $T_{4}$ hormone had significant effect on absolute growth weight, total length and their specific growth rate (Heraedi et al., 2018). Meanwhile, in adult brood stock, treatment of $10 \mathrm{mg}$ of $\mathrm{T}_{4} \mathrm{~kg}$ body per weight in Sterlet sturgeon which were intraperitoneally injected could promote biochemical and metabolic changes in the broodstock that were associated with enhanced egg fertility and larval survivability (Abdollahpour et al., 2019). Keeping in view the above, this study was carried out to determine the effect of $\mathrm{T}_{4}$ hormone on the growth and survival of climbing perch larvae through $\mathrm{T}_{4}$ immersion technique.

\section{Materials and Methods}

Induced breeding : A pair of male and female climbing perch broodstock was injected with Ovaprim (Syndel, Canada) inducing hormone. The male and female broodstock were weighed to measure the correct dosage of hormone, $0.5 \mathrm{ml} \mathrm{kg}^{-1}$ for female fish and $0.25 \mathrm{ml} \mathrm{kg}^{-1}$ for male fish, respectively. The fish were anesthetized using MS222 before the hormone was injected into the fish.

Both male and female broodstock were placed in a tank for $24 \mathrm{hrs}$. The top of the tank was covered with a net to ensure that the fish did not jump out due to aggression after hormone injection. After $24 \mathrm{hrs}$, the broodstock were taken out and transferred into broodstock tanks. The incubation tank was vigorously aerated until the larvae hatched (within $24 \mathrm{hr}$ ). Healthy fertilized eggs were transparent in the incubation tank and unfertilized eggs were white in colour. The unfertilized eggs were removed to avoid fungal growth that could affect other eggs. After $24 \mathrm{hrs}$ of incubation, fish larvae hatched and aeration slowed down. Gentle aeration was allowed just to give enough oxygen to newly hatched larvae for their growth.

Feeding of larvae : Growing larvae of climbing perch were fed with large live feed organisms such as Moina sp. and Daphnia sp. or supplied with artificial pellets. The weaning process was performed when changing the fish diet from live feed to an artificial diet, as the fish could adjust their feeding behavior from time to time. Experimental care and feeding regime during larvae rearing were fixed, water was changed frequently for the first and second weeks to maintain good water quality. Approximately, 50 $80 \%$ water was changed every day to avoid stress on the larvae. Larvae were fed with live feed twice a day (morning and evening) ad libitum until the end of larvae stages following artificial feed during juvenile period. The environmental condition was adjusted to a natural photoperiod at $27^{\circ} \mathrm{C}$, with $12 \mathrm{hr}$ light and $12 \mathrm{hr}$ dark photoperiod, respectively.

Treatment of different frequency of Thyroxine $\left(T_{4}\right)$ hormone: Two weeks after hatching and rearing in normal conditions, the climbing perch larvae were assigned into four different groups with different frequencies of hormone treatments. Each group 
was performed in triplicates, where each triplicate consisted of 40 fish larvae. The different treatments of $T_{4}$ were: Group 1: $1 \times 0.5$ ppm $\mathrm{T}_{4}$, Group 2: 2X 0.5 ppm $\mathrm{T}_{4}$, Group 3: $3 \times 0.5$ ppm $\mathrm{T}_{4}$ and Group 4: Control ( 0 ppm $\mathrm{T}_{4} / 0.7 \%$ saline). Different concentration was prepared for $0 \mathrm{ppm} \mathrm{T}_{4}$ ( 1 I of $0.7 \%$ saline water) and $0.5 \mathrm{ppm}$ $\mathrm{T}_{4}(0.5 \mu \mathrm{g}+1$ l of $0.7 \%$ saline water $)$.

During the treatment, each group of larvae was immersed in the specific $T_{4}$ treatment for $30 \mathrm{~min}$. $T_{4}$ treatment was given once a week for three continuous weeks. After each treatment, the larvae were transferred into rearing $5 \mathrm{I}$ aquarium tanks based on their assigned groups and were fed ad libitum, using Moina sp. during larvae stages, and artificial pellets after they entered fingerling stage. The experiment was carried out for seven weeks, and the observation data on growth and survival of larvae in each group was recorded weekly.

Growth and survival data : Data of climbing perch larvae were taken every week. Water parameters were taken using YSI multimeter. Several parameters including dissolved oxygen, unionized ammonia, $\mathrm{pH}$ and temperature before water changing process were also recorded for data analysis. The unionized ammonia should be less than $0.05 \mathrm{mg} \mathrm{l}^{-1}$ in the water as increase in ammonia may lead to mortality. The survival and mortality of fish were observed every week and compared between each treatment.

The length of climbing perch larvae was taken every week under a light microscope. Three fish samples were collected randomly from each tank were sacrificed every week for measuring the length, weight and physical appearance (skin coloration) The fins and scales were also observed to determine if there were any differences during the culture period. Comparison between each treatment was observed to indicate the best frequency of treatments towards climbing perch larvae. The measurement of length was taken before treatments were applied to each group.

As larvae grew into juveniles, the pigmentation of climbing perch between treatments was observed until the end of the experiment. The coloration of fish scales and formation of black spots were observed at the caudal peduncle of fish. Skin pigmentations were compared using a scale bar; which consists of a low, medium and high graduation to evaluate the differences in development between fish treatments (Fig. 1).

At Week 4, fish from each treatment were weighed for data collection. Fish weight was taken using weighing balance before feeding, and the weight was compared between treatments. The length of fish was measured with a vernier calipers and observed under compound microscope. The experiment was terminated at Week 7 , the final lengths and weights were taken for data analysis. Similar to the lengths taken the weight was also taken before treatments were applied to each group.
MEDIUM

STRONG

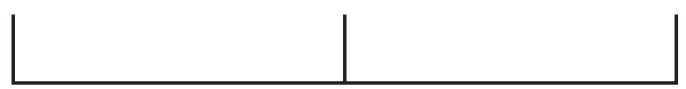

Weak : no black spot at caudal peduncle, pale yellow, no lateral line formation, no black lining on the body, no scales.

Medium : black spot at caudal peduncle nearly seen, yellowish in color, black lining can be seen but no so clear, lateral line can be seen, scales formation.

Strong : black spot at caudal peduncle can be seen clearly, yellowish to greenish in color, scales can be seen clearly, lateral line appear fully, black lining can be seen from caudal peduncle to the head, black spot at the operculum.

Fig. 1 : Scoring scale that was used to classify differences in growth and skin pigmentation based on physical characteristic of climbing perch larvae. Important features including the scales formation, fin and rays development and skin pigmentation was recorded for data analysis.

Statistical analyses : Data analysis of length and weight of each group of climbing perch was analyzed by one-way ANOVA with SPSS software (IBM® SPSS $\otimes$ Statistic version 21). Post hoc test using Duncan was performed when there was a significant difference at $p<0.05$ between each group. For survival rate, the graph was plotted on the percentage of survival every week. All data were expressed as mean $\pm \mathrm{SE}$.

\section{Results and Discussion}

This study was carried out to observe the effects of $T_{4}$ hormone on climbing perch (Anabas testudineus) larvae. Previous studies have reported that treatment $T_{4}$, which is the most stable form of thyroid hormones as compared to $T_{3}$ (Norris and Carr, 2013), showed positive effect towards fish larvae, by helping the larvae to fasten the egg yolk absorption into the body, increased growth rate and enhanced morphological differentiation for fish larvae (Mukhi et al., 2007; Yamano, 2005; Hirata et al., 1989). A study on Nile tilapia (Sarotherodon niloticus) fry revealed that treatment with $\mathrm{T}_{4}$ increased the yolk absorption of fish larvae and increased the growth of larvae significantly (Yamano, 2005; Nacario, 1983). In milkfish (Chanos chanos), the larvae treated with $\mathrm{T}_{4}$ hormone showed stimulation of growth and development in the fish, where the total length and dry weight of the fish increased in comparison to the control treatment (Lam et al., 1985).

Thyroxine hormone can also promote skin pigmentation of fish larvae during the larvae-juvenile transition phase (Suliman and Flamarique, 2014; Leclercq et al., 2010). In this study, the reference for the development of climbing perch larvae was based on the scale bar that had been described in Fig. 1 to classify the fish growth and its development, while the observation of physiological appearance and skin coloration of climbing perch larvae is shown in Fig. 2. Thyroxine treatment was 
Treatments

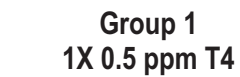

Week 1

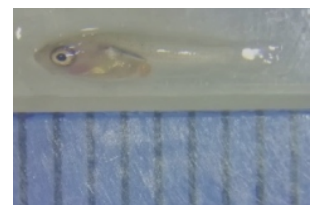

Image 2Ai Weak

Week 2

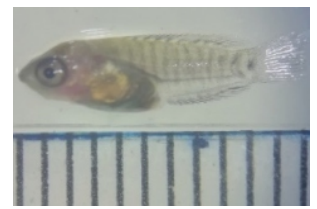

Image 2Bi Medium

Week 3

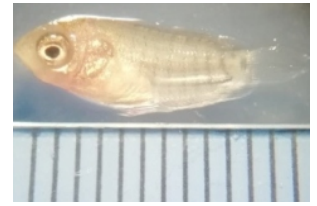

Image 2Ci Medium

Week 4

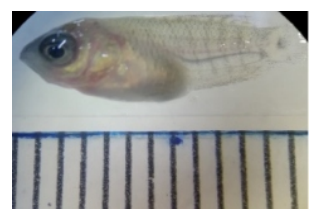

Image 2Di Strong

Week 5

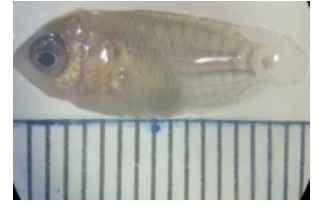

Image 2Ei Strong

Week 6

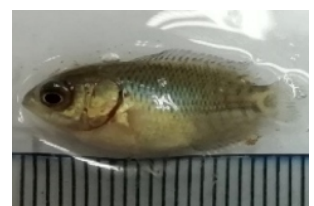

Image 2Fi Strong

Week 7

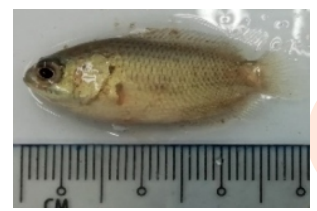

Image 2Gi Strong
Group 2

2X 0.5 ppm T4

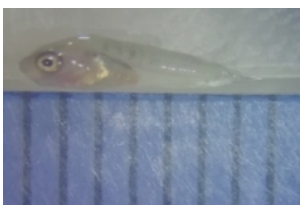

Image 2Aii Weak

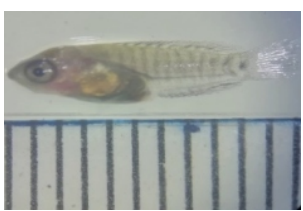

Image 2Bii Medium

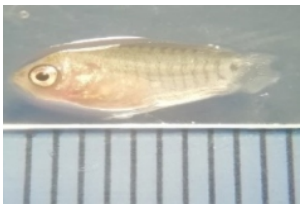

Image 2Cii Medium

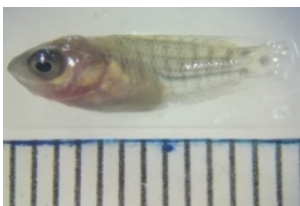

Image 2Dii Strong

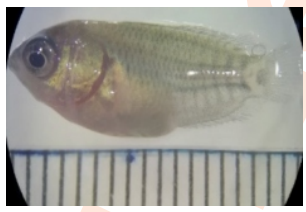

Image 2Eii Strong

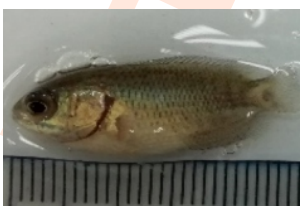

Image 2Fii Strong

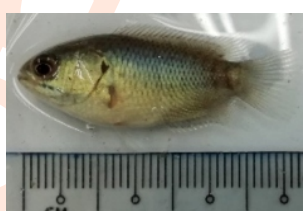

Image 2Gii Strong
Group 3

3X 0.5 ppm T4

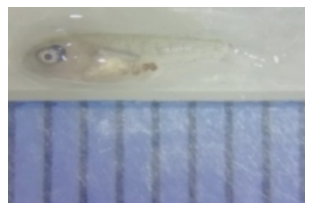

Image 2Aiii Weak

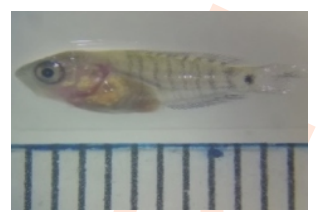

Image 2Biii Medium

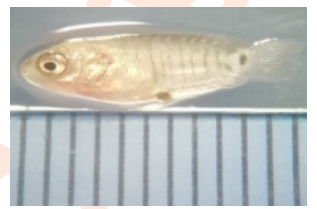

Image 2Ciii Medium

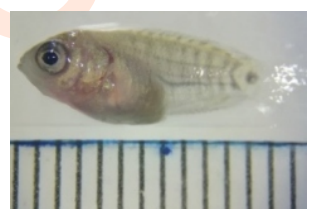

Image 2Diii Medium

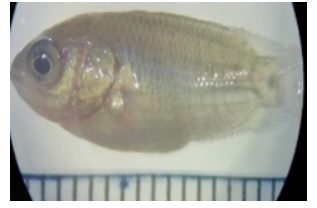

Image 2Eiii Strong

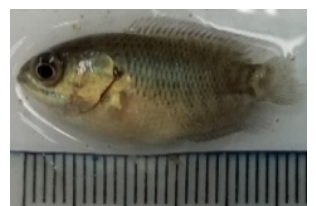

Image 2Fiii Strong

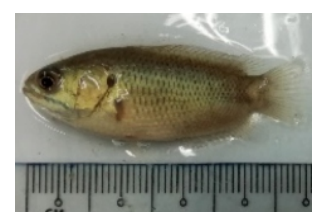

Image 2Giii Strong
Group 4 control, 0 ppm T4

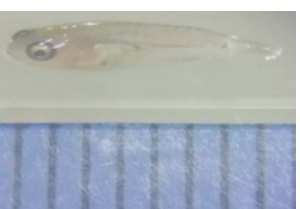

Image 2Aiv Weak

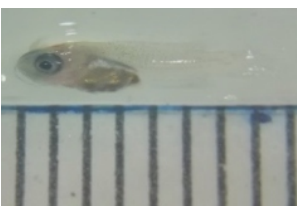

Image 2Biv Weak

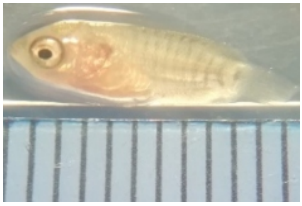

Image 2Civ Medium

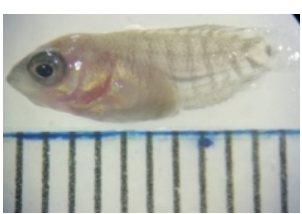

Image 2Div Medium

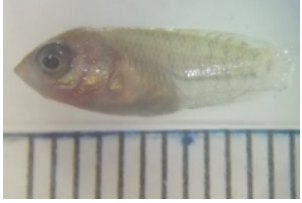

Image 2Eiv Medium

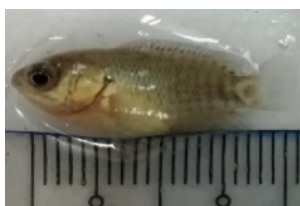

Image 2Fiv Strong

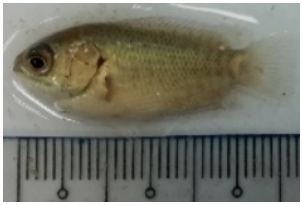

Image 2Giv Strong

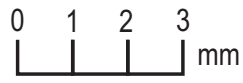

Fig. 2 : Growth, skin pigmentation and physical characteristic of climbing perch larvae based on the scoring scale in Fig. 1 (Strong: black spot at caudal peduncle can be seen clearly, yellowish to greenish in color, scales can be seen clearly, lateral lines fully appear, black lining can be seen from caudal peduncle to the head and black spot at the operculum; Medium: black spot at caudal peduncle nearly seen, yellowish in color, black lining can been seen but still unclear, lateral lines can be seen and scales formation; and Weak: no black spot at caudal peduncle, pale yellow, no lateral line formation, no black lining and no scale on the body). Observation was performed once a week from Week 1 until Week 7 . Four groups with different $T_{4}$ treatments were performed viz., Group 1: 1X0.5 ppm T, Group 2: 2 X0.5 ppm T, Group 3: 1 X0.5 ppm T and Group 4: control (0.7\% saline). 


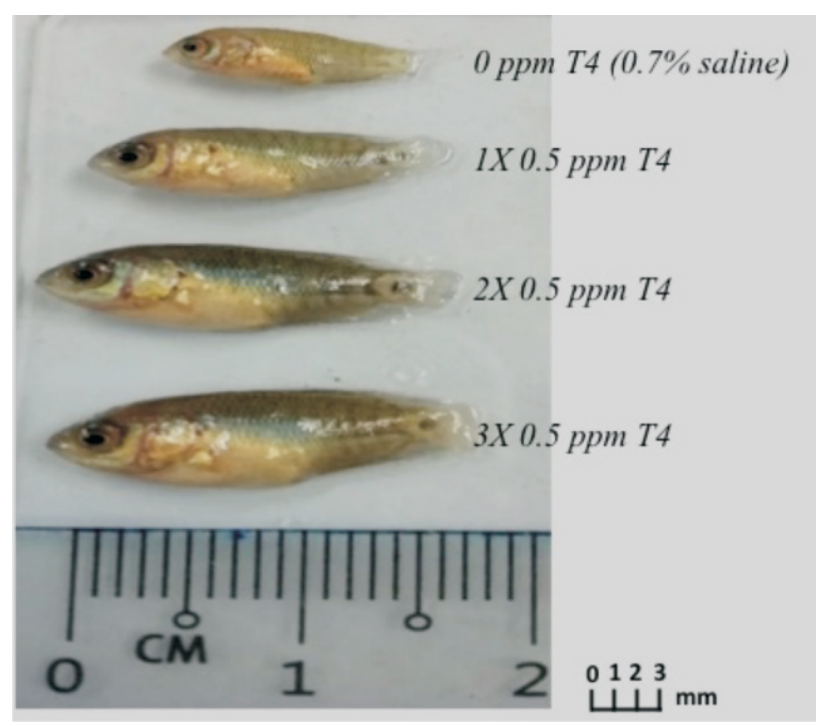

Fig. 3 : Fish from four different groups were aligned together to observe the difference in length. First row: Group 4 (control, $0 \mathrm{ppm} \mathrm{T}_{4}$ ); Second row: Group 1 (1X $0.5 \mathrm{ppm} \mathrm{T}_{4}$ ); Third row: Group 2 (2X $\left.0.5 \mathrm{ppm} \mathrm{T}_{4}\right)$; and Fourth row: Group 3 ( $3 \times 0.5 \mathrm{ppm} \mathrm{T}_{4}$. Fish treated with $\mathrm{T}_{4}$ hormone grew bigger with good coloration.

started from Week 1 until Week 3, once in every seven days. Four different treatments were performed, where Group 1: 1X $0.5 \mathrm{ppm}$ $\mathrm{T}_{4}$, Group 2: 2X $0.5 \mathrm{ppm} \mathrm{T}_{4}$, Group 3: 3X 0.5 ppm T4 and Group 4: Control ( $0 \mathrm{ppm} \mathrm{T}_{4} / 0.7 \%$ saline). In Week 1 , before the treatment, majority of the larvae were at Weak scale, where there were no black spots at the caudal peduncle, the color of larvae was nearly pale or yellow, no lateral line formation, no black lining on the body and no scales on their body. In the following week (Week 2), the fish groups treated with first treatment of $\mathrm{T}_{4}$ (Group 1, Group 2 and Group 3) showed differences in their appearance as compared to Group 4 (control). $T_{4}$ groups reached at Medium scale, where a black spot at caudal peduncle was nearly seen, the larvae were yellowish, a lateral line and a black lining can been seen though it was still unclear and the formation of the scales was also observed on the larvae. In Week 4, Group 2 and Group 3 in which the larvae had been treated with two and three $\mathrm{T}_{4}$ treatments, the physiological appearance and coloration had reached at Strong scale, while Group 1 and Group 4 (control) still at the Medium scale. Majority of larvae at Group 2 and Group 3 had a black spot on their caudal peduncle, the larvae were yellowish to greenish color, scale formation was clearly seen, lateral lines and black lining could be seen from the caudal peduncle to the head and black spots could be detected at the operculum. In Week 5 , all $T_{4}$ treated groups (Group 1, Group 2 and Group 3) reached at Strong scale, while Group 4 (control) still at Medium scale. On Week 6 and Week 7, the larvae from all groups (Group 1, Group 2, Group 3 and Group 4) had completely morphed into a juvenile fish. The coloration was strongly formed and the physical character of the fish had resembled into adult climbing perch. However, the length and weight of fish differed between $T_{4}$ and non- $T_{4}$ treated group (Fig. 3). From this experiment, fish that were not treated with T4 hormone developed skin pigmentation slower at the early stages compared to the fish that treated with T4 hormone. Skin coloration in $T_{4}$ treated fish had started to develop physical feature that indicated a mini adult fish at the beginning of Week 4 of larval rearing. The formation of dark spots on the fish body and fin and development of rays were also spotted earlier in $T_{4}$ treated fish groups.

Our study showed that $0.5 \mathrm{ppm}$ of $\mathrm{T}_{4}$ hormone is the best dose to treat climbing perch larvae to improve their growth. This study focused on the frequencies of $\mathrm{T}_{4}$ immersion to enhance the fish growth. The larvae were reared up to ten days before treatment, due to their tendency to tolerate stress when treatments were applied at early stage. From the data recorded from Week 1 until Week 7, different frequencies of $T_{4}$ immersion showed differences in growth pattern of climbing perch larvae based on their length and weight (Table 1). On the first week before $T_{4}$ immersion, no significant difference was observed between all treatment groups. Following Week 2 until Week 7 , significant difference in length of $\mathrm{T}_{4}$ treated groups was noted when compared to the non-treated $\mathrm{T}_{4}$ group. On Week 5, Group 3, which had been treated with $3 \times 0.5 \mathrm{ppm} \mathrm{T}_{4}$, recorded the highest and significant increase $(18.71 \mathrm{~cm})$ as compared to Group 1: 1X $0.5 \mathrm{ppm} \mathrm{T}_{4}(16.09 \mathrm{~cm})$, Group 2: $2 X 0.5 \mathrm{ppm} \mathrm{T}_{4}(17.39 \mathrm{~cm})$ and Group 4: control ( $14.74 \mathrm{~cm})$. From Week 6 and Week 7 , the larvae treated with $\mathrm{T}_{4}$ grew significantly different as compared to the untreated $T_{4}$ (control group). Between those three frequencies, the highest mean length and weight values were recorded in fish treated with two and three times of $\mathrm{T}_{4}$ hormone (Fig. 4 and Fig. 5). There was also significant difference in weight gained between $\mathrm{T} 4$ treated fish and non- $\mathrm{T}_{4}$ treated fish. However, no statistically significant difference was noted in fish weights within the frequencies of $T_{4}$ treatment groups. This result is in line with previous studies who demonstrated that only a small dosage of $\mathrm{T}_{4}$ hormone ( $\left.0.5 \mathrm{ppm}\right)$ was sufficient to enhance the metamorphosis in fish larvae (Campinho et al., 2017; Heraedi et al., 2018). In addition, the effectiveness of $\mathrm{T}_{4}$ treatment was based on the experimental condition that applied by the researcher, where the results of other studies may differ with reference to the methods of administration, fish species or $\mathrm{T}_{4}$ preparation (Jones et al., 2017; Manzon and Manzon, 2017). Throughout the experiment, no significant difference was observed among the treatment groups, Group 1: 1X $0.5 \mathrm{ppm} \mathrm{T}_{4}$, Group 2: $2 \times 0.5 \mathrm{ppm}$ $\mathrm{T}_{4}$, Group 3: $3 X 0.5 \mathrm{ppm} \mathrm{T}_{4}$ and Group 4: Control (0 ppm $\mathrm{T}_{4} / 0.7 \%$ saline), in dissolved oxygen, $\mathrm{pH}$ value, unionized ammonia and water temperature, indicated the experiment was carried out under controlled conditions (Table 2).

In this experiment, treated $\mathrm{T}_{4}$ climbing perch larvae developed its special morphological characteristics such as hard 

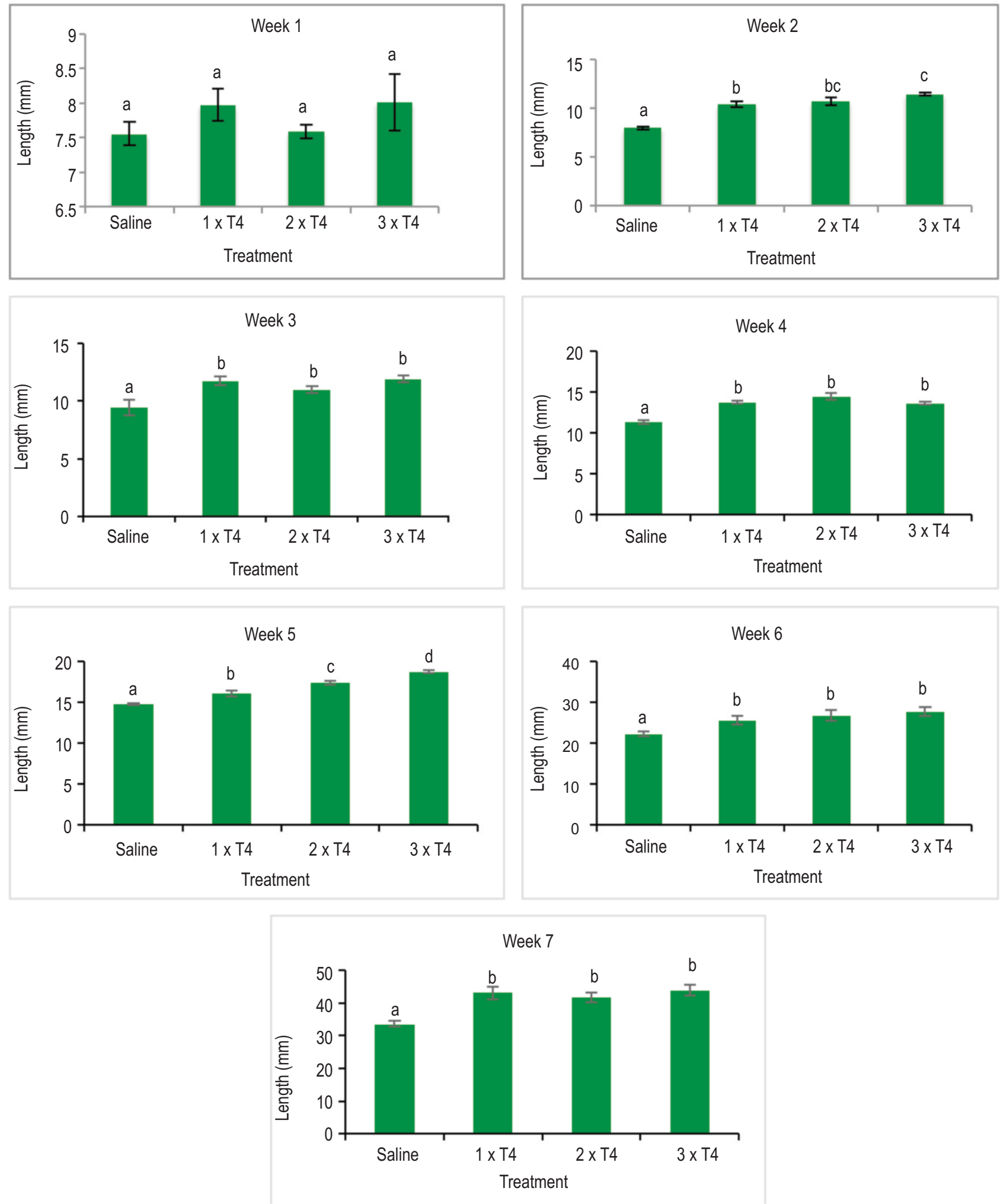

Fig. 4 : The length of climbing perch larvae were plotted in bar graph to analyze the mean length of larvae from Week 1 until Week 7 . Four groups with different T4 treatments were performed, which Saline $\left(0.7 \%\right.$ saline), $1 \times 0.5 \mathrm{ppm} \mathrm{T}_{4}, 2 \mathrm{X} 0.5 \mathrm{ppm} \mathrm{T}_{4}$ and $3 \times 0.5 \mathrm{ppm} \mathrm{T}_{4}$. Different letters refer to statistically significant differences, $p<0.05$. All values are mean + SEM. From the results, the highest mean length values were recorded in fush treated with two and three times of $\mathrm{T}_{4}$ hormone. 
Table 1 : Data recorded for length and weight of climbing perch larvae at different concentration of T4 treatments

\begin{tabular}{|c|c|c|c|}
\hline Weeks & Treatment & Length (mm) & Weight (g) \\
\hline \multirow[t]{4}{*}{ Week 1} & Group 11X0.5 ppm T4 & $7.968 \pm 0.235^{\mathrm{a}}$ & ND \\
\hline & Group 22X 0.5 ppm T4 & $7.585 \pm 0.100^{\mathrm{a}}$ & ND \\
\hline & Group 33X0.5 ppm T4 & $8.015 \pm 0.410^{\mathrm{a}}$ & ND \\
\hline & Group 4 (control)Saline/ 0 ppm T4 & $7.553 \pm 0.171^{\mathrm{a}}$ & ND \\
\hline \multirow[t]{4}{*}{ Week2 } & Group $11 \times 0.5$ ppm T4 & $10.396 \pm 0.285^{b}$ & ND \\
\hline & Group $22 \times 0.5$ ppm T4 & $10.690 \pm 0.432^{b}$ & ND \\
\hline & Group 33X0.5 ppm T4 & $11.451 \pm 0.194^{b}$ & ND \\
\hline & Group 4 (control)Saline/ 0 ppm T4 & $7.980 \pm 0.131^{\mathrm{a}}$ & ND \\
\hline \multirow[t]{4}{*}{ Week3 } & Group $11 X 0.5$ ppm T4 & $11.755 \pm 0.375^{b}$ & ND \\
\hline & Group 22X0.5 ppm T4 & $10.958 \pm 0.282^{\mathrm{ab}}$ & ND \\
\hline & Group 33X0.5 ppm T4 & $11.885 \pm 0.293^{b}$ & ND \\
\hline & Group 4 (control)Saline/ 0 ppm T4 & $9.412 \pm 0.704^{a}$ & ND \\
\hline \multirow[t]{4}{*}{ Week 4} & Group $11 \times 0.5$ ppm T4 & $13.755 \pm 0.191^{b}$ & $0.062 \pm 0.006^{b}$ \\
\hline & Group 22X0.5 ppm T4 & $14.420 \pm 0.405^{b}$ & $0.050 \pm 0.003^{\mathrm{ab}}$ \\
\hline & Group 33X0.5 ppm T4 & $13.632 \pm 0.158^{b}$ & $0.057 \pm 0.002^{\mathrm{ab}}$ \\
\hline & Group 4 (control)Saline/ 0 ppm T4 & $11.290 \pm 0.239^{\mathrm{a}}$ & $0.041 \pm 0.002^{\mathrm{a}}$ \\
\hline \multirow[t]{4}{*}{ Week 5} & Group $11 \times 0.5$ ppm T4 & $16.095 \pm 0.330^{b}$ & $0.106 \pm 0.020^{\mathrm{ab}}$ \\
\hline & Group 22X 0.5 ppm T4 & $17.385 \pm 0.227^{\circ}$ & $0.107 \pm 0.013^{\mathrm{ab}}$ \\
\hline & Group 33X0.5 ppm T4 & $18.707 \pm 0.191^{d}$ & $0.161 \pm 0.029^{b}$ \\
\hline & Group 4 (control)Saline/ 0 ppm T4 & $14.735 \pm 0.123^{\mathrm{a}}$ & $0.067 \pm 0.007^{\mathrm{a}}$ \\
\hline \multirow[t]{4}{*}{ Week 6} & Group $11 \times 0.5$ ppm T4 & $25.527 \pm 1.073^{\mathrm{ab}}$ & $0.444 \pm 0.084^{\mathrm{a}}$ \\
\hline & Group 22X 0.5 ppm T4 & $26.735 \pm 1.339^{b}$ & $0.378 \pm 0.092^{\mathrm{a}}$ \\
\hline & Group 33X0.5 ppm T4 & $27.677 \pm 1.035^{\mathrm{b}}$ & $0.493 \pm 0.685^{a}$ \\
\hline & Group 4 (control)Saline/ 0 ppm T4 & $22.262 \pm 0.657^{\mathrm{a}}$ & $0.252 \pm 0.017^{\mathrm{a}}$ \\
\hline \multirow[t]{4}{*}{ Week7 } & Group $11 \times 0.5$ ppm T4 & $43.048 \pm 1.865^{b}$ & $1.260 \pm 0.169^{\mathrm{ab}}$ \\
\hline & Group $22 \times 0.5$ ppm T4 & $41.753 \pm 1.486^{b}$ & $1.472 \pm 0.031^{\mathrm{b}}$ \\
\hline & Group 33X 0.5 ppm T4 & $43.877 \pm 1.563^{b}$ & $1.335 \pm 0.274^{\mathrm{ab}}$ \\
\hline & Group 4 (control)Saline/ 0 ppm T4 & $33.463 \pm 0.939^{\mathrm{a}}$ & $0.703 \pm 0.044^{\mathrm{a}}$ \\
\hline
\end{tabular}

$N D$ : no data recorded; Value (means $\pm S E M)$ in the same column with different superscripts were significantly different $(p<0.05)$.

Table 2 : Water quality parameters throughout the culture period of climbing perch larvae at different concentrations of T4 treatments

\begin{tabular}{lllll}
\hline & Group 1 (1X0.5 ppm T4) & Group 2 (2X0.5 ppm T4) & Group 3 (3X0.5 ppm T4) & Group 4 (control, saline/ 0 ppm T4) \\
\hline Dissolve oxygen $\left(\mathrm{mgl}^{-1}\right)$ & $6.909 \pm 0.161^{\mathrm{a}}$ & $6.869 \pm 0.160^{\mathrm{a}}$ & $6.744 \pm 0.223^{\mathrm{a}}$ & $6.722 \pm 0.228^{\mathrm{a}}$ \\
$\mathrm{pH}$ & $7.690 \pm 0.104^{\mathrm{a}}$ & $7.641 \pm 0.099^{\mathrm{a}}$ & $7.660 \pm 0.091^{\mathrm{a}}$ & $7.763 \pm 0.112^{\mathrm{a}}$ \\
Ammonia $\left(\mathrm{mgl}^{-1}\right)$ & $0.018 \pm 0.003^{\mathrm{a}}$ & $0.013 \pm 0.003^{\mathrm{a}}$ & $0.144 \pm 0.003^{\mathrm{a}}$ & $0.015 \pm 0.003^{\mathrm{a}}$ \\
Temperature $\left({ }^{\circ} \mathrm{C}\right)$ & $26.449 \pm 0.096^{\mathrm{a}}$ & $26.465 \pm 0.097^{\mathrm{a}}$ & $26.551 \pm 0.104^{\mathrm{a}}$ & $26.442 \pm 0.098^{\mathrm{a}}$ \\
\hline
\end{tabular}

Values in the same row with same superscripts are not significantly different with $(p>0.05) \pm S E M$

operculum and specialized lungs that enable them to crawl from one place to another place, more advanced as compared to nontreated $\mathrm{T}_{4}$ climbing perch larvae. This advantage gave climbing perch to endure open air for a period of time (Peter et al., 2011). Besides, the survival of climbing perch larvae also increased when treated with $\mathrm{T}_{4}$ hormone (Fig. 6).

Untreated larvae showed poor survivability before it transformed into juvenile fish. Due to late growth of fish, thus delaying the development of their immunity system. Incomplete immunity system made the fish susceptible to bacterial and fungul infection. Quesada-García et al. (2014) reported that the fish immune organ like thymus, spleen and excretory kidney are associated with thyroid for developing immunity system in most teleost.

From this study, the results indicated $T_{4}$ treatment could increase the growth and development, pigmentation and survival rate of climbing perch larvae. Larvae treated with $T_{4}$ hormone at one or two times at $0.5 \mathrm{ppm}$ showed a significant development and have a better coloration compared to the untreated $T_{4}$ fish. 

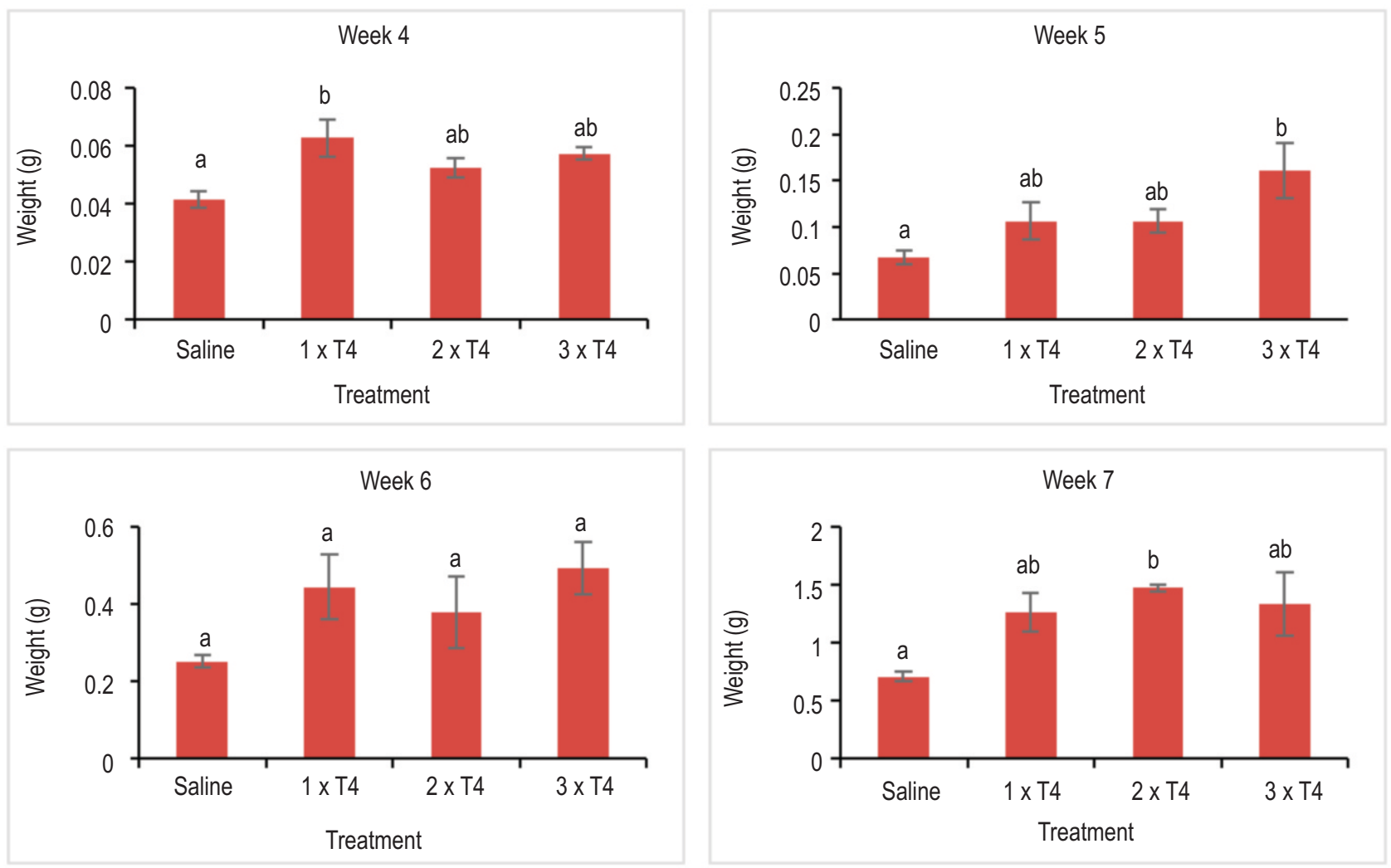

Fig. 5 : The weight of climbing perch were plotted in bar graph to analyze the mean weight of larvae from Week 1 until Week 7 . Four groups with different T4 treatments \{Saline ( $0.7 \%$ saline), 1 X $0.5 \mathrm{ppm} \mathrm{T4,2X} 0.5 \mathrm{ppm}$ T4 and 3X $0.5 \mathrm{ppm} \mathrm{T4 \} .} \mathrm{Different} \mathrm{letters} \mathrm{refer} \mathrm{to} \mathrm{statistically} \mathrm{significant} \mathrm{differences,}$ $p<0.05$. All values are means \pm SEM. From the results, the highest mean length values were recorded in fush treated with two and three times of $T_{4}$ hormone.

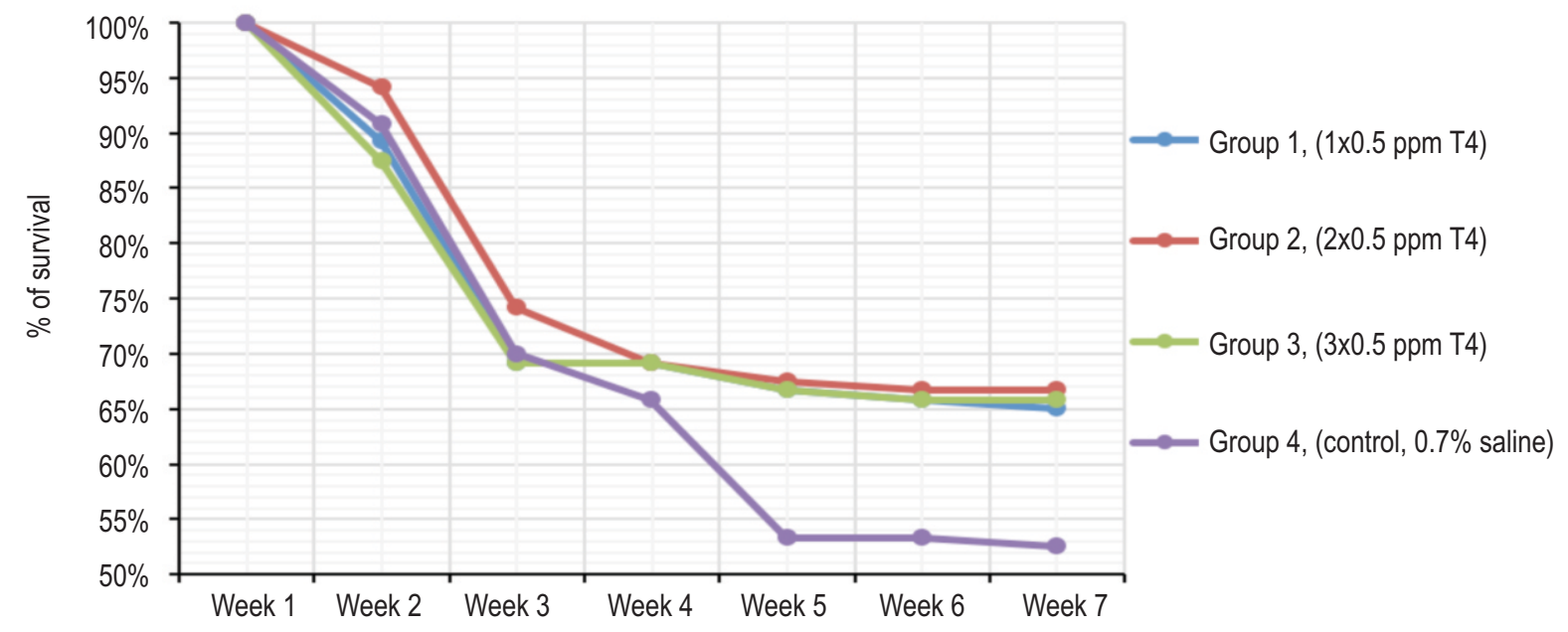

Fig. 6 : Survival rate of climbing perch larvae after seven weeks of larvae rearing with different T4 treatments (Group 1: 1X 0.5 ppm T4, Group 2: 2 X 0.5 ppm T4, Group 3: 1 X0.5 ppm T4 and Group 4: control (0.7\% saline).

The fish showed positive growth pattern and it could fasten the fish rearing period to reach the commercial size ( 1.5 inch). Therefore, treatment of fish using $T_{4}$ hormone could significantly reduce the cost of nursing period, and could increase the production of climbing perch to fulfill the market demand in Malaysia and in other Asian countries. 


\section{Acknowledgments}

This work was supported by the Geran Putra IPM, Universiti Putra Malaysia (GrantNo.: GP-IPM/2017/9575600). We would like to thank all the students and laboratory staff of Laboratory of Biotechnology Aquatics, Department of Aquaculture, Faculty of Agriculture, Universiti Putra Malaysia for their kind assistanceand technical support throughout this project.

\section{References}

Abdollahpour, H., B. Falahatkar, I. Efatpanah, B. Meknatkhah and G. Van Der Kraak: Hormonal and physiological changes in Sterlet sturgeon Acipenser ruthenus treated with thyroxine. Aquaculture, 507, 293-300 (2019).

Campinho, M.A., M.G. Burgos, G.E. Sweeney and D.M. Power: Coordination of deiodinase and thyroid hormone receptor expression during the larval to juvenile transition in sea bream (Sparus aurata, Linnaeus). Gen. Comp. Endocrinol., 165, 181-194 (2010).

Chang, J., M. Wang, W. Gui, Y. Zhao, L. Yu and G. Zhu: Changes in thyroid hormone levels during zebrafish development. Zool. Sci., 29, 181-184 (2012).

Department of Fisheries Malaysia: Annual Fisheries Statistic 2017 Volume 1. Ministry of Agriculture and Agro-Based Industry Malaysia, Putrajaya (2017).

Dickhoff, W.W., C.L. Brown, C.V. Sullivan and H.A. Bern: Fish and amphibian models for developmental endocrinology. J. Exp. Zool., 256, 90-97 (1990).

Dolomatov, S. and R. Medical: Role of thyroid hormones in fishes. J. Hlth. Sci., 3, 279-296 (2013).

FAO (Fisheries and Aquaculture Department): The future of the food and agriculture: Trends and challenges. Food and Agricultural Organization of the United Nations, Rome (2017).

Heraedi, A., S.B. Prayitno and T. Yuniarti: The effect of different thyroxine hormone (T4) concentration on the growth, survival, and pigment development of pink zebra fish larvae (Brachydanio reiro). OmniAkuatika, 14, 21-28 (2018).

Hirata, Y., H. Kurokura, S. Kasahara and R. January: Effect of thyroxine and thiourea on the development of larval Red Sea Bream Pagrus major. Nippon Suisan Gakk., 55, 1189-1195 (1989).

Hughes, G.M., S.C. Dube and J.D. Munshi: Surface area of the respiratory organs of the climbing perch, Anabas testudineus (Pisces: Anabantidae). J. Zool., 170, 227-243 (1973).

Jamsari, A.F., Z.A. Muchlisin, M. Musri and M.N. Siti Azizah: Remarkably low genetic variation but high population differentiation in the climbing perch, Anabas testudineus (Anabantidae), based on the mtDNA control region. Genet. Mol. Res., 9, 1836-1843 (2010).

Jones, R.A., W.B. Cohn, A.A. Wilkes and D.S. MacKenzie: Negative feedback regulation of thyrotropin subunits and pituitary deiodinases in red drum, Sciaenops ocellatus. Gen. Comp. Endocrinol., 240, 19-26 (2017).
Kobayashi, M., S. Msangi, M. Batka, S. Vannuccini, M.M. Dey and J.L. Anderson: Fish to 2030: The role and opportunity for aquaculture. Aquac. Econ. Manag., 19, 282-300 (2015).

Lam, T., Juario and Banno: Effect of thyroxine on growth and development in post yolk-sac larvae of milkfish. Aquaculture, 46,179-184 (1985).

Leclercq, E., J.F. Taylor and H. Migaud: Morphological skin colour changes in teleosts. Fish Fish., 11, 159-193 (2010).

Manzon, R.G. and L.A. Manzon: Molecular and cellular endocrinology lamprey metamorphosis: Thyroid hormone signaling in a basal vertebrate. Mol. Cell. Endocrinol., 459, 28-42 (2017).

Morioka, S., S. Ito, S. Kitamura and B. Vongvichith: Growth and morphological development of laboratory-reared larval and juvenile climbing perch Anabas testudineus. Ichthyol. Res., 56, 162-171 (2009).

Mukhi, S., L. Torres and R. Patiño: Effects of larval-juvenile treatment with perchlorate and co-treatment with thyroxine on zebrafish sex ratios. Gen. Comp. Endocrinol., 150, 486-494 (2007).

Nacario, J.F.: The effect of thyroxine on the larvae and fry of Sarotherodon niloticus L. (Tilapia nilotica). Aquaculture, 34, 73-83 (1983).

Norris, D.O. and J.A. Carr: The hypothalamus-pituitary-thyroid (HPT) axis of non-mammalian vertebrate. In: Vertebrate Endocrinology (Eds: D.O. Norris and J.A. Carr). London: Academic Press, p 231 (2013).

Peter, M.C.S., J. Leji and V.S. Peter: Ambient salinity modifies the action of triiodothyronine in the air-breathing fish Anabas testudineus Bloch: Effects on mitochondria-rich cell distribution, osmotic and metabolic regulations. Gen. Comp. Endocrinol., 171, 225-231 (2011).

Power, D.M., L. Llewellyn, M. Faustino, M.A. Nowell, B.T. Björnsson, I.E. Einarsdottir, A.V.M. Canario and G.E. Sweeney: Thyroid hormones in growth and development of fish. Comp. Biochem. Physiol. C. Toxicol. Pharmacol., 130, 447-459 (2001).

Quesada-García, A., A. Valdehita, C. Kropf, A. Casanova-Nakayama, H. Segner and J.M. Navas: Thyroid signaling in immune organs and cells of the teleost fish rainbow trout (Oncorhynchus mykiss). Fish Shellfish Immun., 38, 166-174 (2014).

Rosman, F.N. and Z. Zulperi: Effect of a commercial rice pesticide on embryonic and larval development of climbing perch (Anabas testudineus). Int. J. Biosci., 15, 272-281 (2019).

Suliman, T. and I.N. Flamarique: Visual pigments and opsin expression in the juveniles of three species of fish (rainbow trout, zebrafish, and killifish) following prolonged exposure to thyroid hormone or retinoic acid. J. Comp. Neurol., 522, 98-117 (2014).

Vidthayanon, C.: Peat swamp fishes of Thailand. Office of Environmental Policy and Planning, Bangkok, Thailand, p. 136. (2002).

Yamano, K.: The role of thyroid hormone in fish development with reference to aquaculture. Jarq-Jpn Agr. Res. Q., 39, 161-168 (2005).

Young, M.A., S. Foale and D.R. Bellwood: Why do fishers fish? A crosscultural examination of the motivations for fishing. Mar. Policy, 66, 114-123(2016). 